\title{
What is connected learning and how to research it?
}

\author{
Kumpulainen, Kristiina
}

2014

Kumpulainen , K \& Sefton-Green , J 2014 , ' What is connected learning and how to

research it? ' , International Journal of Learning and Media , vol. 4 , no. 2 , pp. 7-18 . https://doi.org/10.1162/IJLM_a

http://hdl.handle.net/10138/232913

https://doi.org/10.1162/IJLM_a_00091

cc_by_nc_nd

publishedVersion

Downloaded from Helda, University of Helsinki institutional repository.

This is an electronic reprint of the original article.

This reprint may differ from the original in pagination and typographic detail.

Please cite the original version. 


\section{What Is Connected Learning and How to Research It?}

Kristiina Kumpulainen

University of Helsinki

kristiina.kumpulainen@helsinki.fi

\section{Julian Sefton-Green}

London School of Economics and Political Science

julian@julianseftongreen.net

\section{Keywords}

connected learning

chronotopes

boundary crossing

intertextuality

learning lives
Abstract

Efforts to understand the dynamic processes of learning situated across space and time, beyond the here and now, are presently challenging traditional definitions of learning and education. How can we conceptualize learning in a way that is able to respond to and explain the increasing complexity, connectivity, and velocity of our times? We elaborate on the notion of "connected learning" as a conceptual heuristic that has recently received recognition as a potential lens and a model through which to research and promote learning as a holistic experience that stretches beyond formal and informal communities. We reflect on the methodological challenges of describing, defining, and analyzing connected learning across young peoples' everyday "learning lives" from the sociocultural and dialogic perspectives. We discuss such key notions for connected learning as understanding, tracking, and tracing learners; chronotopes; boundary crossing; intertextuality; and learning lives. 


\section{Introduction}

Efforts to understand the dynamic processes of learning situated across space and time, beyond the here and now, are presently challenging traditional definitions of learning and education. How can we conceptualize learning in a way that is able to explain the increasing complexity, connectivity, and velocity of our times? What transformations are necessary in education in order to better respond to the learning lives and learning processes that young people experience across different contexts? In this article, we elaborate on the notion of "connected learning" as a conceptual heuristic that has recently received recognition as a potential lens and model through which to research and promote learning as a holistic experience that stretches beyond formal and informal communities (Ito et al. 2013).

A growing number of researchers from scholarly fields such as education, literacy and media studies, and learning research are pursuing research agendas that involve investigating learning as a series of boundary-crossings in and across social spaces (home, school, and peer cultures; in and out of school) and epistemic practices (formal, informal, authorized, unauthorized). Many of these researchers share a common perception that, in order to understand learning, learners and their situated social practices must be a point of departure, encompassing their learning transitions across contexts; that is, a connected learning perspective. While interest in connected learning as a way to harness the interest-driven energies of learners has been considerable in academic, policy, and innovation circles (Sefton-Green et al. 2011), researchers still find describing how connected learning takes place to be challenging (Leander, Phillips, and Taylor 2010).

All contexts of learning, including classrooms as well as local and virtual communities, are centers of multifaceted and complex activities. They are places where intensive social, cognitive, and cultural mediation occurs as knowledges and subjectivities meet, cross, and resist one another (Rex, Steadman, and Graciano 2006). A learning context is nested in multiple worlds occupied by the same people, who simultaneously take on different roles and strive for different purposes (Shulman 1986). Understanding learning from a connected perspective challenges research even more, since here we are interested in understanding the nature of learning not only within a setting but within a matrix and continuum of several communities and contexts. The complexities of researching connected learning are also addressed by contemporary literacy research, which has directed its focuses on movement and spatiality with the use of digital media (Leander, Phillips, and Taylor 2010). The increased mobility of learning contexts poses key questions about the role of time and scale as well as the idea of spatiality online and offline (Arnseth and Silseth 2013). As Lemke (2004) points out, we have little understanding of how we make sense of things and add to our understandings as we move from one activity to another, from one setting to another, and from one space to another. The complexity of researching connected learning calls for a holistic frame and a diversity of approaches with different levels of analysis (Erstad and Sefton-Green 2013).

This article begins from the premise that forms of connected learning are not only desirable but also set to dominate progressive education reform. Our focus is on the particular methodological questions that arise from setting out to research connected learning, because the field of activity and its phenomena are dispersed and spread wide. By reviewing literature around connected learning, this article offers an understanding of connected learning as dialogical phenomena. We begin by outlining the key characteristics of connected learning and explore in more detail the possibilities for researching subjects over time, boundary crossing, and learning lives. Our aim is to provide a theoretical analysis of connected learning in order to turn the aspiration of researching connected learning into a more grounded and practical activity.

Before we attempt to map out and discuss some of the key principles that might underpin researching connected learning, we note that the current era is characterized by a distinct kind of conservatism in measuring education. Our attempts-as well as those of our fellow contributors to this issue and of colleagues and members of wider movements-to describe new kinds of metrics for understanding learning need to be read in this context (Schwartz and Arena 2013). The last 20 years have seen the rise of a series of international comparisons "benchmarking" performance in standardized testing. Numerous countries have instigated a series of educational reforms at the national level, many of which revolve around a belief in the capacity to assess, measure, and compare performance. In the process, they have defined the outcomes of learning in a narrow fashion. All of these 
reforms suggest a political consensus about the ways in which learning can be defined and "captured" in meaningful ways. Part of the challenge of connected learning is that it undermines the confidence of such judgments. The methods we employ to research connected learning thus, by definition, begin to subject the value of these conservative metrics to wider scrutiny. The question of methodology is not just an arcane concern for researchers but goes to the heart of how we define learning. While we are not suggesting that the principles we explore can be easily transposed into new kinds of measurement-even if that were desirable-we do suggest that they offer other ways of characterizing learning and therefore question common assumptions about defining achievement and progression.

\section{Are Schools Responding to Students' Lives and 21st-Century Learning Requirements?}

The traditional concept of schooling, based on a reproduction model wherein one teacher in one classroom teaches one subject at a time to one class, is increasingly being questioned (e.g., Dumont, Istance, and Benavides 2010; Facer 2011; Säljö 2012). Researchers have long argued that inflexible curricula, textbooks, and teacher talk leave little room for personalized and creative learning practices (Mehan 1979; Leander 2002; Engeström 2008; Kumpulainen, Mikkola, and Jaatinen 2013). Moreover, the dominant model of schooling has been criticized for minimizing the opportunity for long-term intellectual and identity development by disconnecting the study of each subject from all others and by dividing the day into periods defined by a clock rather than by the needs of learning (Lemke 2004). Stakeholders at all levels are increasingly understanding that education must change for 21st-century learners and learning. This understanding calls for broadened access to learning that is socially embedded, interest-driven, and oriented toward educational opportunity (Ito et al. 2013).

The complexity of contemporary society calls for new kinds of educational opportunities to serve the multiplicity of needs of all 21st-century learners. Designing learning environments that respond to students' holistic learning lives and that reconfigure spaces and places of learning is important in today's education where an increasing number of students feel disengaged and disconnected from formal education. Moreover, living and learning in a digital and globalized society requires skills and competencies that cannot be adequately addressed by narrow and product-oriented views of education and schooling. Twenty-first-century learning requirements, such as critical thinking and problem solving, collaboration and communication, creativity, and new literacy and media skills are challenging or even impossible to promote in an educational environment that is restricted in specific space and time and is purely teacher-led and controlled (Lemke 2004; Trilling and Fadel 2009; Kumpulainen et al. 2011).

Today's technologies offer ample possibilities for purposeful integration of tools for social connection and knowledge co-creation and for linking classroom, community, and home. Many schools are equipped with digital and mobile technologies, but the question remains how these technologies are integrated into the curriculum and how they are used to promote meaningful and productive learning that resonates with 21st-century learning requirements and students' holistic learning lives, encompassing their interestdriven practices within and across school, home, peer groups, and other communities (Kemker, Barron, and Harmes 2007; Jonassen et al. 2008; Lim and Chai 2008; Collins and Halverson 2009). In general, students who have access to and use digital media outside the school but do not have the same opportunities at school can easily find schoolwork irrelevant and meaningless. The ultimate issue is how to narrow the gap between how learners live and how and what they learn at school.

\section{What Might 21st-Century Pedagogy and Learning Look Like?}

Reform efforts in education have addressed the importance of extending traditional space-time configurations of schooling and connecting school learning with students' whole learning lives, activities, tools, and identities situated within and across formal and informal settings, including virtual spaces (Brown and Renshaw 2006; McLeod and Yates 2006; Madge et al. 2009). Moreover, in these reforms, school learning is no longer seen as merely repeating what is already known but involves transformations in which something new and formerly unknown is created (e.g., Säljö 2012). Here, learning is understood not as something that takes place exclusively in the restricted spaces of formal education (Hughes, Jewson, 
and Unwin 2007; Ramsten and Säljö 2012); instead learning is situated within a matrix of contexts including formal and informal, local and global, embodied and virtual, as well as distributed and integrated.

Learning environments that extend across space and time, that are responsive to students' learning lives and diverse "funds of knowledge," call for pedagogical innovation and transformation. From the connected learning perspective, focusing educational attention on the links between different spheres of learning can better support interest-driven and meaningful learning (Ito et al. 2013). This requires social, cultural, and technological supports to enable learners to link, integrate, and translate their interests and knowledge(s) across academic, civic, and careerrelevant domains. These expanded learning environments cut across the boundaries that have traditionally separated institutions of education, popular culture, home, and community. Important design principles for such connected learning environments include breaking boundaries between formal and informal; valuing learner agency, authority, and accountability; and stressing the importance of learners pursuing meaningful and authentic activities with relevant resources and tools (Engle and Conant 2002).

Not all learning environments are formally organized and constructed within schooled educational frameworks, however. As a principle for reform, connected learning is particularly interested in exploring "organic" - naturally or socially occurring-forms of learning and informal learning processes in order to understand their principles better and to explore how they can be harnessed in designed and developed educational programs (Ito et al. 2013).

Expanded learning environments that support connected learning can emerge only through sustained collective efforts. For example, without a pedagogical culture that transforms traditional learning practices, digital media is initially likely to represent merely an additional layer of activity (Hakkarainen 2009). Creating innovative learning environments or learning communities is thus not just a matter of implementing and putting into use alternative pedagogical ideas and technologies; in many cases it is also a matter of transforming simultaneously existing social practices. Coevolution of the social and technological infrastructures of education should be the starting point for expanded and connected learning environments and learning opportunities (Kumpulainen, Mikkola, and Jaatinen 2013).
Connected learning is realized when the learner is able to pursue a personal interest or passion with the support of friends, caring adults, and/or expert communities and is in turn able to link this learning and interest to academic achievement, career success, or civic engagement. Here, knowledge and knowing are associated not only with the teacher, the curriculum, or outside experts but with everyone participating. That is, learners are seen by themselves and by others as knowledgeable, committed, and accountable participants whose identities are variable, multivocal, and interactive (Holland et al. 1998; Wenger, McDermott, and Snyder 2002). Learners are held accountable for contributing to authentic problem solving, knowledge co-creation, and learning. In connected learning, learners are provided with opportunities to develop interpersonal relationships and to learn with and from others. These learning environments broaden traditional forms of learner agency and accountability by expanding possibilities for engagement and bringing in new audiences with whom students collaborate and create new knowledge and understanding.

\section{Researching Connected Learning}

From an epistemological point of view, connected learning can be approached as a phenomenon in its own right and/or as an analytic frame. If we can find ways to conceptualize connected learning as discrete phenomena then we need to find ways to observe, capture, and report on these. Equally, if connected learning exists primarily as a way of reconceptualizing learning in the 21st century, then how can we find ways to "see" it and to describe the evidence of our emerging theorizations? We focus on these analytic frames in order to explore whether connected learning poses particular and distinct challenges for researchers and for research methodology. However, this begs the question: To what extent is the way we observe connected learning part of the way we can imagine and frame it? After all, it is partly through the emergence of new and different kinds of research methodology that we can even begin to see and understand new and changing kinds of learning; namely, how links and connections are made across contexts and timespace configurations and how boundaries in and between formal and informal settings are established and managed (Hull and Schultz 2002; Bekerman et al. 2005).

The key challenge for researching connected learning is how to capture the dynamic nature of 
the making of connections, which works at a number of levels. Using connected as an adjective to describe the participle learning implies a certain sense of completed-ness, of the learning being fulfilled by making the connection. The language here is probably inadequate, but the challenge of tracking (or tracing) the processes of connectivity is complex, because we tend to focus on the result of the connection-thus implying that it has been made-rather than the interactions of the process. Although this might sound unnecessarily abstract and more like the challenges involved in exploring phenomena such as electrical circuits, we do need a form of social science that is capable of isolating and describing the making of connections across traditionally discrete boundaries.

\section{The Sociocultural Paradigm}

In this article, we examine the notion of connected learning from the sociocultural and discursive perspectives shaped by ethnographic and sociolinguistic orientations (Vygotsky 1978; Cole 1996; Castanheira et al. 2001; Bloome et al. 2005; Kumpulainen and Renshaw 2007). Using this framework, we understand connected learning to be a social construct that emerges in interaction while learners engage in various social practices mediated by different artifacts. In this framework, culture is seen as a situated resourcea fund of knowledge and a repertoire of practice and competence-that learners draw upon to make sense of their social and material worlds and to participate in them (Spindler 1974).

Our thinking is also related to the social ecology notion that learning is a complex, reciprocal process dependent on constructive, culturally relevant interactions between learners and their social ecologies (Barron 2004). A social ecology is defined as a set of interacting contexts in students' lives that mediate their learning and social activities. Each of these contexts comprises a unique configuration of the activities, material resources, relationships, and interactions that emerge therein (Barron 2006).

This framework guides our analyses of the ways in which children and youth learn within and across contexts and how what they learn is co-figured by the specific types of activities they participate in, as well as the social, symbolic, and material resources they use (Star and Griesemer 1989; Gonzáles, Moll, and Amanti 2005; Greeno 2006; Walker and Nocon 2007). Focusing on the social practices and discourses of learners across space and time directs our analyses of both the affordances of and constraints on participation and learning.

In the sociocultural perspective, learning is viewed as participation in cultural practices. The notion of learning-as-participation directs our attention to the processes of engagement in situated activities. Engagement and learning become evident and are continuously reconstructed in the social life of different communities, reflected in the legitimate ways of participation and communication (Vygotsky 1978; Wells 1999; Wenger 1998). Learning is thus defined as being able to distinguish between different contexts and their discourses as well as being able to participate successfully in those contexts by harnessing relevant practices and discourses. The local, momentby-moment interactions signal what counts as learning, participating, and communicating. Although it conceives of learning as situated meaning-making reflected in qualitatively different participation practices, this perspective emphasizes the role of social interaction and discourse in knowledge creation and learning. By taking social activity and discourse as the core units of analysis, this perspective breaks down the conceptual barrier between the individual and the social.

\section{Analytical Principles for Investigating Connected Learning}

Three kinds (or, perhaps, levels) of connection need to be captured to be able to provide meaningful evidence about connected learning. The first of these are research methodologies that can capture duration and process. These are ways of observing change over time within and across space-time configurations. The second are research methodologies, which can capture movements across boundaries and places and, in particular, across complementary social spaces and domains. This also entails the idea that intertextuality can help us explore the process of cross-referencing and dialogue implicit in any conceptualization of making connections in situated practice. The third is research that analyzes individuals" "learning lives," that assesses them holistically as they grow, change, and bring together different experiences, including life-wide and life-long learning.

\section{Time, "Growing Up," Progression, and Epistemic Practices}

Observing and theorizing change over time is a "classical" problem in educational research. An interest 
in examining how learners revisit and reapply learning experiences, either over different time periods or in the idea of modeling progressions in conceptual understanding and practical application, is not new. While connected learning is, on the whole, not especially interested in a normative "ages and stages" idea of growing up, nor is it focused on devising developmentalist principles, it is focused on how experiences might be revisited and reflected on over different time periods. In addition, it is interested in the ways in which traditionally discrete knowledge domains might be recalibrated and used both in different contexts and over different time periods.

This focus poses a number of research challenges. The most obvious is how to track discrete experiences, followed by how to account for their transformations in other time frames. Connected learning thus requires access to various timescales (i.e., to its subjects' reflections and projections, accounts of which only they can provide). The connected learning research subject is often accorded far more authority in the research process and often co-constructs research data. This is partly a matter of the changing power status of research subjects within the social sciences and partly because of the fact that, without highly motivated and committed participation in the research process, the extraction of these sorts of traces would be impossible because only the research subject knows about the relevant role of experiences beyond the timeframe of the research process.

Other dimensions of time, such as intensity of experience (often equating to frequency of observation) and memory, as well as the methodologies to revisit and return to episodes and moments are all part and parcel of methods for capturing change over time. The conventional educational research paradigm, which focuses on episodes or moments in classrooms (e.g., Bloome et al. 2005) is significantly expanded by an approach that attempts to link such moments or episodes into longer-term narratives. Yet, at the same time, the bounded notion of a learning experience can seem endless and uninformed - as shown by recent investigations into the digital afterlife; that is, the ways that blogging and social media perpetuate what used to be finite experiences (Soep 2010).

\section{Chronotopes}

The construct of the chronotope allows us to examine and understand the processes and development over time of connected learning by focusing on how people understand and conceptualize their collective and individual movements through time and space (Bloome et al. 2005; Brown and Renshaw 2006). The concept can be traced back to the work of Bakhtin (1981), who defines the spatiotemporal matrix as being produced, shaped, and reshaped by the discourses of the participants as they relate to spaces and times beyond here and now. In his work, Bakhtin captures the temporal and spatial situatedness of human actions.

Chronotopes can be defined as socially constructed practices that are closely interconnected in time and space (Bakhtin 1981). They are defining features of a culture or a subculture, because they inform our design choices in shaping social-institutional spaces for particular use (Lemke 2004). The chronotope is marked by changes in the tempo of an ongoing activity, and it permits us to explain variation in the pace and the emerging organization of an activity. The situated, dynamic processes evolve through the interaction of past, present, and future (Brown and Renshaw 2006; Ligorio and Ritella 2010). Following Lemke (2004) and Bloome and associates (Bloome et al. 2009), we hold that within schools and classrooms there exist not only institutionally established chronotopes but new, emerging forms of chronotopes that develop over time. In addition, new chronotopes do not simply replace the old ones; for example, conventional and novel chronotopes can live side-by-side in contemporary schooling (Leander 2002; Kumpulainen and Lipponen, 2013; Kumpulainen, Mikkola, and Jaatinen 2013).

Bakhtin scholars Emerson and Holquist define the chronotope as a unit of analysis for studying language according to the ratio and characteristics of the temporal and spatial categories represented in that language (see Bakhtin 1981). Specific chronotopes are said to correspond to particular genres, or relatively stable ways of speaking, which themselves represent particular worldviews and ideologies. To this extent, a chronotope can be regarded as both a cognitive concept and a narrative feature of language. The distinctiveness of chronotopic analysis, in comparison to most other uses of time and space in language analysis, stems from the fact that Bakhtin privileges neither time nor space - they are utterly interdependent and should be studied independently.

The concept of the chronotope has provided several researchers with a conceptual lens through which to investigate learner agency and engagement in 
social activity within and across formal and informal settings (Lemke 2004; Brown and Renshaw 2006; Bloome et al. 2009). The concept has been used to illuminate learners' agency as they collectively explore and negotiate their experiences, understandings, and relationships mediated by their past experiences, ongoing involvement, future aspirations, and goals (Kumpulainen and Lipponen 2013). In these studies chronotopes have been defined as spaces in which learners' agency and identities are negotiated as they move both physically and psychologically to different spaces and time scales.

\section{Contexts, Boundaries, and Locations}

The second key area for research into connected learning is that of boundary crossing, a conceptual and theoretical term that captures the activities and dynamics of reapplying and reframing learning from one context to another. Connected learning is particularly focused on those moments and experiences where knowledge from one domain is applied in another. In general, boundary crossing is interested in the complexities, barriers, and enablers involved in the process, as well as the host of issues related to selfregulation and the "rules" that pertain to any notion of transgression or opportunity in such activities. A key problematic in the extensive corpus around the boundary crossing is the challenge of what defines the boundary, and this in turn means questioning the nature of context (Arnseth and Silseth 2013).

Identifying, describing, and defining the contextual nature of the context is also challenging (Edwards 2009). One of the weaknesses in the idea of connected learning is that it is too inclusive: that everything contributes to learning and that, since learning is something we tend to do much of the time, the challenge for connected learning is to distinguish a general state of learning-readiness from a specific and discrete learning that is particular. Thus, while all learning is contextual, specific and particular elements of context contribute to, and are necessary for, forms of connected learning.

Tracking or tracing the movements and the processes of crossing the borders between contexts is not a completely open process. Connected learning is particularly focused on the capability to make connections across experiences-it is general in this senseand it is particularly focused on a model of autonomy and agency as well as a range of social interactions.
Connected learning also emphasizes mediating and translating epistemic practices and knowledge domains from one context to another. Research needs to be able to capture the processual and the dynamic (Drotner 2013); it needs to be able to objectively disentangle context and boundary-these are descriptive challenges - and to be able to account for the problems involved in these travels; and it needs to be able to capture that moment of newness where, having arrived in a different place, learners can orientate themselves to the new challenge.

A recent review of literature on boundary crossing and boundary objects by Akkerman and Bakker (2011) reveals four potential learning mechanisms that can take place at boundaries: (1) identification, which is about coming to know what the diverse practices are about in relation to one another; (2) coordination, which is about creating cooperative and routinized exchanges between practices; (3) reflection, which is about expanding one's perspectives on the practices; and (4) transformation, which is about collaboration and codevelopment of (new) practices. These mechanisms demonstrate ways in which sociocultural differences and resulting discontinuities in action and interaction can come to function as resources for learning and development of intersecting identities and practices.

Akkerman and Bakker stress, however, the importance of acknowledging that engagement at the boundary does not stand for a fusion of intersecting social worlds and boundaries. For them, boundary crossing should not be seen as a process of moving from initial diversity and multiplicity to homogeneity and unity but rather as a process of establishing continuity in a situation of sociocultural difference. This holds also for the transformation mechanism.

These processes of crossing boundaries should be viewed as opening new horizons for learning and identity building. A challenge for education might be to enhance boundary permeability by creating possibilities for participation, interaction, and collaboration across a diversity of sites and contexts, both within and across institutions.

\section{Intertextuality}

Intertextuality-that is, reference or juxtapositioning made by speakers to other texts in their acts of communication (Bloome and Egan-Robertson 1993) provides one fruitful conceptual tool with which to 
investigate and understand connected learning as learners move across boundaries while making sense of the world in their local, moment-by-moment interactions. By following social interactional and microethnographic approaches (e.g., Bloome et al. 2005), intertextual analysis can help researchers understand which intertextual connections arise during social interaction in a given social context. This entails analyzing not only the emergence of intertextuality during situated social interaction but also whether and how intertextuality is acknowledged, recognized, and granted social significance within and across contexts and situations.

For Bakhtin (1981), language is not a neutral medium appropriated by the speaker, because every word holds a cultural meaning determined by the multiple contexts in which it has lived its socially tuned life. Intertextuality refers to the social construction of relationships among contexts past, present, and future. Across time and events, a consequential progression shapes texts, practices, and knowledges. A word, phrase, stylistic device, or other textual feature in one text refers to another text; two or more texts share a common referent or are related because they are of the same genre or belong to the same setting or because one text leads to another. The idea that any text indexes many others, that it is imbued with the voices of many people and past texts, is today a commonplace (Bloome et al. 2005).

The social construction of intertextuality always occurs within a cultural context that influences which texts may be juxtaposed how, where, and when and by whom. The cultural norms related to intertextual substance, intertextual process, and entitlement rights can consequently support and also constrain the knowledge base of the activity, how that knowledge base is distributed during the activity, and what may happen within the activity (Bloome and EganRobertson 1993). To research intertextuality is thus also to address the relationship between micro-level contexts (specific events and situations) and macrolevel contexts (broad social and cultural structures). Intertextual analysis provides insights into the relationship of micro- and macro-level contexts and is a conceptual tool for describing such relationships (Bloome et al. 2005).

Whereas scholarship on intertextuality has tended to focus on written texts, a growing body of research studies intertextuality in conversational texts, electronic texts, and nonverbal texts, among others. These empirical investigations of intertextuality illuminate, for example, how relationships between texts and events are constructed in classroom literacy events as well as how these connections are ratified by others and which social consequences result from this.

Intertextuality has also been used to analyze the social construction of disciplinary learning. A study by Kumpulainen, Vasama, and Kangassalo (2003) illuminated how students make sense of science in inquiry classrooms by examining learners' construction of science-related explanations and their intertextual connections. This study illuminated how intertextual links functioned as tools for the students (a) to share and validate previous experiences as sources of knowledge, (b) to establish reciprocity with one another in meaning-making, (c) to define themselves as learners of science and as individuals with specific experiences and backgrounds, and (d) to construct, maintain, and contest the cultural practices of what it means to do and learn science in the classroom. Another study on intertextuality in a classroom followed a learner-centered, integrated science literacy unit and showed how the active making of links and connections to texts while thinking and talking about science concepts helped young science learners create spaces in which to grapple with complex ideas and ways of expressing them (Varelas, Pappas, and Rife 2006).

\section{Learning Lives}

The third principle of research required for investigating connected learning is that of "learning lives." This phrase has come to stand for an emphasis on studying individuals, cohorts, and generations in considerable individual depth as a way of exploring the journey and travel of learning and experience. This frame offers a way of thinking holistically about learning for life and thus deliberately differentiates its approach from the instrumental skills-based definitions of learning so prominent in educational discourse. In addition, this frame carries with it a particular sense of the challenges offered by new economic and social relationships emerging in the 21st century. These revolve around a deferral of financial independence and family responsibilities (young people are now much less likely to be able to move away from home and afford their own accommodation); an understanding of a much longer period of apprenticeship into employment; the changing nature of that employment (now much more uncertain and mobile); a relationship with 
a globalized employment market; a changing relationship with the welfare state; and a focus on the project of the self as being the outcome of education with a commitment to becoming a lifelong learner (see the contributions in Erstad and Sefton-Green 2013).

Many of these changes are daunting and problematic and do not necessarily portend a growth-filled future. They do, however, point toward a different kind of discipline wherein learners need to be flexible and develop a range of interpersonal and presentational skills, as well as be adaptable, resilient, opportunistic, and entrepreneurial. These capabilities do not diminish the value of traditional academic knowledge or academic skills. To the contrary, we believe they will become as highly regarded and important in measuring what counts in education. Research thus needs to be able to capture and theorize these changing subjectivities. We need ways of describing and observing the development of forms of subjectivity, of selfhood rather than simple academic performance (Thomson 2009).

Learning lives projects set out to examine individuals in their relationships with and to immediate social groupings and local communities (McLeod and Yates 2006; Thomson 2009). They focus on placemaking and on individuals' sense of their sociogeographical horizons (MacLeod 2008; Dillabough and Kennelly 2010). They are as interested in "horizontal" learning experiences-that is, those experienced across contexts and time periods-as they are in the development and progression of the self "vertically" through time. Researchers involved in these projects are thus deeply interested in developing extended case studies, methods of portraiture, and forms of ethnographic narrative (McLeod and Thomson 2009). In addition, methodology needs access to more-sophisticated theory exploring the processes of individualization and identity-making so that learning can be situated within the matrix of processes that are involved in the making of the modern self. Life history and biography are often part of the suite of methods involved (e.g., Goodson and Sikes 2001; West et al. 2007; Alheit 2009). Here, "sampling" from the moments across the life course and returning to notions of progression and change both within key learning frames (i.e., compulsory schooling) and across key transitions (e.g., leaving school and entering work) lead to an emphasis on pathways and trajectories - of social routes (McLeod and Thomson 2009). Projects undertaken by one of this article's au- thors and by colleagues in this special issue exemplify research projects in this tradition (see London School of Economics, Department of Media and Communications 2011; University of Oslo, Department of Education 2010).

\section{Conclusions}

In this article, we have illuminated the ways that socioculturally and discursively informed research can provide conceptual tools for researching and understanding what counts as connected learning. Although much current policy interest starts from the premise that we learn life-wide, life-deep, and lifelong, how do we then "locate" the learner, and, equally important, how do young people see themselves as learners? And how can we research this? Furthermore, how do we conceptualize who the learner is and where learning is taking place and with what purpose, all while concentrating on the task of locating learners as they appear constituted through interactions with digital technologies across home, school, and other sites?

"Following" learners across and between sites either physical (as in home/school/youth provision/with peers) or virtual (as in gaming, social networks, or via mobile technologies) or conceptually (tracing, translating, and reconfiguring understandings across contexts) is self-evidently complex and difficult (Leander et al. 2010). Methodological challenges are simultaneously practical—how to track and physically follow learners; ethical and legalhow to ensure access and trust across social domains; and conceptual-what constitutes evidence of learning (Bloome et al. 2005; Wortham 2008; Erstad et al. 2009)? And how can the movement of learning be traced and observed in translation? All of these challenges are framed by the need to develop appropriate kinds of theorization of connected learning-itself a project that can proceed only in tandem with the development of pertinent methodologies in order to construct a meaningful intellectual framework.

Understanding and supporting the engagement of children and youth in learning is vital in a time of social and economic crisis; it is important as a way of offering new perspectives on the value on narrowly defined performance-driven assessments. Young people's competence in moving between settings and in taking an active role in learning has significant implications for the quality of their lives. Such competences can be 
a great resource for youth in entering the job-market, in starting a professional life, and for their well-being in general. Through our research and development work we hope to open up avenues for research and educational practice that promote connected learning and the holistic learning lives of children and youth. A focus on learning lives and connected learning is likely to impact the very concept of learning itself.

\section{References}

Akkerman, S., and A. Bakker. 2011. Boundary crossing and boundary objects. Review of Educational Research 82 (4):132-69. doi:10.3102/0034654311404435.

Alheit, P. 2009. Biographical learning-Within the new lifelong learning discourse. In Contemporary theories of learning: Learning theorists in their own words, ed. K. Illeris, 16-128. Abingdon: Routledge.

Arnseth, H. C., and K. Silseth. 2013. Tracing learning and identity across sites: Tensions, connections and transformations in and between everyday and institutional practices. In Identity, community and learning lives in the digital age, ed. O. Erstad and J. Sefton-Green, 23-38. Cambridge, UK: Cambridge University Press.

Bakhtin, M. 1981. The dialogic imagination. Four essays by M. M. Bakhtin. Austin: University of Texas Press.

Barron, B. 2004. Learning ecologies for technological fluency: Gender and experience differences. Journal of Educational Computing Research 31 (1):1-36.

Barron, B. 2006. Interest and self-sustained learning as catalysts of development: A learning ecology perspective. Human Development 99:193-224.

Bekerman, Z., N. C. Burbules, D. S. Keller, and D. SilbermanKeller. 2005. Learning in places: The informal education reader. New York: Peter Lang.

Bloome, D., and A. Egan-Robertson. 1993. The social construction of intertextuality and classroom reading and writing. Reading Research Quarterly 28:303-33. doi: $10.2307 / 747928$.

Bloome, D., S. P. Carter, B. M. Christian, S. Otto, and N. Shuart-Faris. 2005. Discourse analysis and the study of classroom language and literacy events: A microethnographic perspective. Mahwah, NJ: Lawrence Erlbaum Associates Publishers.

Bloome, D., M. Beierle, M. Grigorenko, and S. Goldman. 2009. Learning over time: Uses of intercontextuality, collective memories, and classroom chronotopes in the construction of learning opportunities in a ninthgrade language arts classroom. Language and Education 23 (4):313-34. doi:10.1080/09500780902954257.

Brown, R., and P. Renshaw. 2006. Positioning students as actors and authors: A chronotopic analysis of collaborative learning activities. Mind, Culture, and Activity 13 (3):247-59. doi:10.1207/s15327884mca1303_6.

Castanheira, M. L., T. Crawford, C. Dixon, and J. Green. 2001. Interactional ethnography: An approach to studying the social construction of literate practices. Linguistics and Education 11 (4):353-400. doi:10.1016/S0898-5898(00)00032-2.

Cole, M. 1996. Culture in mind. Cambridge, MA: Harvard University Press.

Collins, A., and R. Halverson. 2009. Rethinking education in the age of technology: The digital revolution and schooling in America. New York: Teachers College Press.

Dillabough, J.-A., and J. Kennelly. 2010. Lost youth in the global city: Class, culture, and the urban imaginary. London: Routledge.

Drotner, K. 2013. Processual methodologies and digital forms of learning. In Identity, community, and learning lives in the digital age, ed. O. Erstad and J. Sefton-Green, 39-56. New York: Cambridge University Press.

Dumont, H., D. Istance, and F. Benavides, eds. 2010. The nature of learning: Using research to inspire practice: Center for Educational Research and Innovation. Paris: OECD.

Edwards, R. 2009. Introduction: Life as a learning context? In Rethinking contexts for learning and teaching, ed. R. Edwards, G. Biesta, and M. Thorpe, 1-13. London: Routledge.

Engeström, Y. 2008. From teams to knots: Activity-theoretical studies of collaboration and learning at work. Cambridge, UK: Cambridge University. doi:10.1017/ CBO9780511619847.

Engle, R. A., and F. C. Conant. 2002. Guiding principles for fostering productive disciplinary engagement: Explaining an emergent argument in a community of learners classroom. Cognition and Instruction 20 (4):399-483. doi:10.1207/S1532690XCI2004_1.

Erstad, O., and J. Sefton-Green, eds. 2013. Identity, community, and learning lives in the digital age. New York: Cambridge University Press.

Erstad, O., O. Gile, J. Sefton-Green, and K. Vasbo. 2009. Exploring "learning lives": Community, identity, literacy and meaning. Literacy 43 (2):100-106. doi:10.1111/j.1741-4369.2009.00518.x.

Facer, K. 2011. Learning futures: Education, technology and social change. London: Routledge.

Gonzáles, N., L. C. Moll, and C. Amanti. 2005. Funds of knowledge: Theorizing practices in households, communities, and classroom. Mahwah, NJ: L. Erlbaum Associates.

Goodson, I. F., and P. J. Sikes. 2001. Life history research in educational settings: Learning from lives. Milton Keynes, UK: Open University Press.

Greeno, J. G. 2006. Authoritative, accountable positioning and connected, general knowing: Progressive themes in understanding transfer. Journal of the Learning Sciences 15 (4):537-47. doi:10.1207/s15327809j1s1504_4.

Hakkarainen, K. 2009. A knowledge-practice perspective on technology-mediated learning. International Journal of Computer-Supported Collaborative Learning 4 (1):213-31. doi:10.1007/s11412-009-9064-X.

Holland, D., W. Lachicotte, D. Skinner, and C. Cain. 1998. Identity and agency in cultural worlds. Cambridge, MA: Harvard University Press.

Hughes, M., N. Jewson, and L. Unwin, eds. 2007. Communities of practice: Critical perspectives. Abingdon, UK: Routledge. 
Hull, G., and K. Schultz. 2002. School's out! Bridging out-ofschool literacies with classroom practice. New York: Teachers' College Press.

Ito, M., K. Gutierrez, S. Livingstone, B. Penuel, J. Rhodes, K. Salen, et al. 2013. Connected Learning: An agenda for research and design. Irvine, CA: Digital Media and Learning Research Hub. http://dmlhub.net/sites/default/files/ ConnectedLearning_report.pdf.

Jonassen, D. H., J. Howland, R. M. Marra, and D. Crismond. 2008. Meaningful learning with technology. 3rd ed. Upper Saddle River, NJ: Pearson Merrill Prentice Hall.

Kemker, K., A. E. Barron, and J. C. Harmes. 2007. Laptop computers in the elementary classroom: Authentic instruction with at-risk students. Educational Media International 44 (4):305-21. doi:10.1080/ 09523980701680888.

Kumpulainen, K., and L. Lipponen. 2013. Crossing boundaries in dialogic learning: A chronotopic analysis of learners' agency work. In Interplays between dialogical learning and dialogical self, ed. M. Cesar and B. Ligorio, 193-217. Charlotte, NC: Information Age Publishing.

Kumpulainen, K., and P. Renshaw. 2007. Culture and learning: A special theme issue. International Journal of Educational Research 46 (3-4):109-15. doi:10.1016/j.ijer.2007.09.009.

Kumpulainen, K., S. Vasama, and M. Kangassalo. 2003. The intertextuality of children's explanations in a technology-enriched early years science classroom. International Journal of Educational Research 39:793-805. doi:10.1016/j.ijer.2004.11.002.

Kumpulainen, K., L. Krokfors, L. Lipponen, V. Tissari, J. Hilppö, and A. Rajala. 2011. Learning bridges-Toward participatory learning environments. Helsinki: CICERO Learning, University of Helsinki.

Kumpulainen, K., A. Mikkola, and A.-M. Jaatinen. 2013. The chronotopes of technology-mediated creative learning practices in an elementary school community. Learning, Media and Technology 39 (1):53-74. doi:10.1080/17439884.2012.752383.

Leander, K. 2002. Polycontextual construction zones: Mapping the expansion of schooled space and identity. Mind, Culture, and Activity 9 (3):211-37. doi:10.1207/S15327884MCA0903_04.

Leander, K. M., N. C. Phillips, and K. H. Taylor. 2010. The changing social spaces of learning: Mapping new mobilities. Review of Research in Education 34 (1):329-94. doi:10.3102/0091732X09358129.

Lemke, J. 2004. Learning across multiple places and their chronotope. http://www-personal.umich.edu/ jaylemke/papers/aera_2004.htm (accessed April 27, 2010).

Ligorio, M. B., and G. Ritella. 2010. The collaborative construction of chronotopes during computer-supported collaborative professional tasks. International Journal of Computer-Supported Collaborative Learning 5 (4):433-52 doi:10.1007/s11412-010-9094-4.

Lim, C. P., and C. S. Chai. 2008. Rethinking classroomoriented instructional development models to mediate instructional planning in technology enhanced learning environments. Teaching and Teacher Education 24 (8):2002-13. doi:10.1016/j.tate.2008.05.004.

London School of Economics, Department of Media and Communications. 2011. Social networking and the changing practices of learning among youth. http:// www2.1se.ac.uk/media@lse/research/The\%20Class.aspx (accessed February 6, 2014).

MacLeod, J. 2008. Ain't no making it: Aspirations and attainment in a low-income neighborhood. 3rd rev. ed. Boulder, CO: Westriew.

Madge, C., J. Meek, J. Wellens, and T. Hooley. 2009. Facebook, social integration and informal learning at university: "It is more socialising and talking to friends about work than for actually doing work." Learning, Media and Technology 34 (2):141-55. doi:10.1080/ 17439880902923606.

McLeod, J., and R. Thomson. 2009. Researching social change: Qualitative approaches. London: SAGE Publications.

McLeod, J., and L. Yates. 2006. Making modern lives. New York: State University of New York Press.

Mehan, H. 1979. Learning lessons: Social organization in the classroom. Cambridge, MA: Harvard University Press.

Ramsten, A.-C., and R. Säljö. 2012. Communities, boundary practices and incentives for knowledge sharing? A study of the deployment of a digital control system in a process industry as a learning activity. Learning: Culture and Social Interaction 1 (1):33-44. doi:10.1016/j.1csi.2012.04.001.

Rex, L., S. Steadman, and M. Graciano. 2006. Researching the complexity of classroom interaction. In Complementary methods for research in education, ed. J. Green, G. Camilli, and P. Elmore, 727-72. Washington, DC: American Educational Research Association.

Säljö, R. 2012. Schooling and spaces for learning. In Learning, social interaction and diversity-Exploring identities in school practices, ed. E. Hjörne, G. van der Aalsvoort, and G. de Abreu, 9-14. Rotterdam: Sense Publishers. doi:10.1007/978-94-6091-803-2_2.

Schwartz, D., and D. Arena. 2013. Measuring what matters most: Choice-based assessments for the digital age. Cambridge, MA: MIT Press.

Sefton-Green, J., P. Thomson, K. Jones, and L. Bresler, eds. 2011. The Routledge international handbook of creative learning. London: Routledge.

Shulman, L. S. 1986. Those who understand: Knowledge growth in teaching. Educational Researcher 15 (2):4-31. doi: $10.3102 / 0013189 \times 015002004$.

Soep, E. 2010. Research methods for Web two dot whoah. In Researching creative learning: Methods and issues, ed. P. Thomson and J. Sefton-Green, 185-96. London: Routledge.

Spindler, G. 1974. Education and cultural process: Toward an anthropology of education. New York: Holt, Rinehart and Winston.

Star, S., and J. Griesemer. 1989. Institutional ecology, "translations" and boundary objects: Amateurs and professionals in Berkeley's Museum of Vertebrate Zoology, 1907-39. Social Studies of Science 19 (3):387-420. doi:10.1177/030631289019003001. 
Thomson, R. 2009. Unfolding lives. Bristol, UK: Policy Press. Trilling, B., and C. Fadel. 2009. 21st century skills: Learning for life in our times. San Francisco: Jossey Bass.

University of Oslo, Department of Education. 2010. Local literacies and community spaces-Investigating transitions and transfers in the "learning lives" of Groruddalen (completed). http://www.uv.uio.no/pfi/english/ research/projects/erstad-learning-lives/index.html (accessed February 6, 2014).

Varelas, M., C. C. Pappas, and A. Rife. 2006. Exploring the role of intertextuality in concept construction: Urban second graders make sense of evaporation, boiling, and condensation. Journal of Research in Science Teaching 43 (7):637-66. doi:10.1002/tea.20100.

Vygotsky, L. S. 1978. Mind in society: The development of higher mental processes, ed. M. Cole, V. John-Steiner, and E. Souberman. Cambridge, MA: Harvard University Press.

Walker, D., and H. Nocon. 2007. Boundary-crossing competence: Theoretical considerations and educational design. Mind, Culture, and Activity 14 (3):178-95 doi:10.1080/10749030701316318.

Wells, G. 1999. Dialogic inquiry: Towards a sociocultural practice and theory of education. Cambridge, UK: Cambridge University Press. doi:10.1017/CBO9780511605895.

Wenger, E. 1998. Communities of practice: Leaming, meaning and identity. Cambridge, UK: Cambridge University Press. doi:10.1017/CBO9780511803932.

Wenger, E., R. McDermott, and W. Snyder. 2002. Cultivating communities of practice: A guide to managing knowledge. Cambridge, MA: Harvard Business School Press.

West, L., P. Alheit, A. S. Andersen, and B. Merrill. 2007. Using biographical and life history approaches in the study of adult and lifelong learning. New York: Peter Lang.

Wortham, S. 2008. Shifting identities in the classroom. In Identity trouble: Critical discourse and contested identities, ed. C. R. Caldas-Coulthard and R. Iedema, 205-28. London: Palgrave. 